\title{
Kinetic Studies of the Hydrolysis of Aromatic Sulphonic Anhydrides
}

\author{
N. HESSELB JERG CHR ISTENSEN
}

\author{
Chemistry Department, Danish Atomic Energy Commission Research Establishment \\ Risф, Denmark
}

\begin{abstract}
The solvolysis of various aromatic sulphonic anhydrides in aqueous acetone and dioxan has been studied kinetically using a stopped-flow apparatus. The reaction mechanism is found to be an $\mathrm{S}_{\mathrm{N}} 2$ hydrolysis. The experimental data are compared with literature data for solvolysis of corresponding sulphonyl chlorides in similar solvents, for which an $\mathrm{S}_{\mathrm{N}} 2$ mechanism also has been established. The higher rates of solvolysis of sulphonic anhydrides compared with sulphonyl chlorides are mainly caused by higher values of the activation entropy.
\end{abstract}

T he solvolysis of sulphonates, $\mathrm{RSO}_{3} \mathrm{R}^{\prime}$, and of sulphonyl chlorides, $\mathrm{RSO}_{2} \mathrm{Cl}$, have been extensively studied in the past, ${ }^{1}$ but no report appears to exist on the solvolysis of sulphonic anhydrides, $\left(\mathrm{RSO}_{2}\right)_{2} \mathrm{O}$. A similar situation does not exist with respect to the carboxyl analogues, RCOOR', RCOCl, and $(\mathrm{RCO})_{2} \mathrm{O}$.

The sulphonic anhydrides form a class of compounds of special interest. They are known to be very reactive, and in certain respects superior as derivating reagents compared to the sulphonyl chlorides. ${ }^{2-4}$ Furthermore, they appear as intermediates in aprotic aromatic sulphonation, a fact with both practical and theoretical consequences. ${ }^{5,6}$

In this paper a report is given of kinetic studies on the hydrolysis of aromatic sulphonic anhydrides in mixtures of water and acetone or dioxan in a temperature range from 15 to $40^{\circ}$. The reactions were followed by conductometric measurements. The fairly high rate of reaction necessitated the use of a stopped-flow apparatus with automatic recording of the conductivity.

\section{EXPERIMENTAL}

Materials. Acetone was fractionated over potassium permanganate. Dioxan was refluxed over sodium for several hours and finally distilled. Water was distilled twice.

$p$-Toluene sulphonic anhydride was prepared from the corresponding acid monohydrate according to Thuneberg. ${ }^{4}$ The monohydrate (Fluka) was transformed into the 
anhydrous acid by evaporation in vacuo at $120^{\circ}$. The residue was treated with $4-6$ weights of thionyl chloride at $90^{\circ}$. After having removed the excess of thionyl chloride the residue was recrystallised several times from benzene-hexane. Benzene sulphonic anhydride was prepared in a similar way, absolute ether being used for the recrystallisation. $p$-Chloro, $p$-bromo-, and $p$-iodo benzene sulphonic anhydrides were prepared by direct sulphonation of the halobenzenes (analytical grade from Fluka and British Drug Houses) with sulphur trioxide in nitromethane, ${ }^{7}$ and subsequently recrystallised from nitromethane. $m$-Nitrobenzene sulphonic anhydride was prepared from the corresponding sulphonyl chloride (British Drug Houses). The chloride was hydrolyzed in boiling water; after evaporation (finally in vacuo) the anhydrous acid was transformed into the sulphonic anhydride by thionyl chloride as described above. The product was recrystallised from benzene.

The identity of the anhydrides was checked by titration with alkali and by determination of the melting points in capillary tubes. The results are given below together with calculated values

\begin{tabular}{|c|c|c|c|c|c|c|}
\hline & $\mathrm{H}$ & $p-\mathrm{CH}_{3}$ & $p-\mathrm{Cl}$ & $p-\mathrm{Br}$ & $p-\mathbf{I}$ & $m-\mathrm{NO}_{2}$ \\
\hline Equiv. wt. found & 151 & 164 & 185 & 228 & 278 & 202 \\
\hline iv. wt. calc & 148 & 163 & 184 & 228 & 275 & 194 \\
\hline found & $86-89^{\circ}$ & $115-125^{\circ}$ & $136-142^{\circ}$ & $179-181^{\circ}$ & $215-218^{\circ}$ & $140-155^{\circ}$ \\
\hline reported & $91.5^{\circ} a$ & $131.5^{\circ} a$ & $141^{\circ b}$ & $182^{\circ b}$ & $221^{\circ b}$ & $160^{\circ} \mathrm{c}$ \\
\hline
\end{tabular}

$a$ Ref. ${ }^{b}$ Ref. $7^{c}$ Ref. 8.

No chloride could be detected by $\mathrm{Ag}^{+}$in the aqueous solutions of the hydrolyzed sulphonic anhydrides.

The sulphonic anhydrides were stored as crystals over phosphorus pentoxide in a vacuum desiccator. Solutions of anhydrides in acetone or dioxan were made up immediately before use.

Description of apparatus. The stopped-flow apparatus was made of glass with connections of polythene and silicone-rubber tubing.

A diagram of the apparatus is shown in Fig. 1. A is a twin glass-syringe consisting of two $5 \mathrm{ml}$ Chance Interchangeable syringes. The two pistons are rigidly connected. Connection from each syringe can be established through 2 three-way valves, B, either to a reservoir $\mathrm{C}$, or to the mixing chamber $\mathrm{D}$. Connections and valves have $1.5 \mathrm{~mm}$ bore. The mixing chamber has a $3.5 \mathrm{~mm}$ inner diameter, and the inlets are arranged tangentially. The mixer is connected to a conductivity cell, $E$, consisting of three platinum rings mounted on the inside of a $4 \mathrm{~mm}$ glass tube (Radiometer, Copenhagen, cell type 114, cell constant $0.62 \mathrm{~cm}$ ). The cell is loaded by an a-c voltage of 0.2 volt and $3 \mathrm{kc} / \mathrm{sec}$, supplied

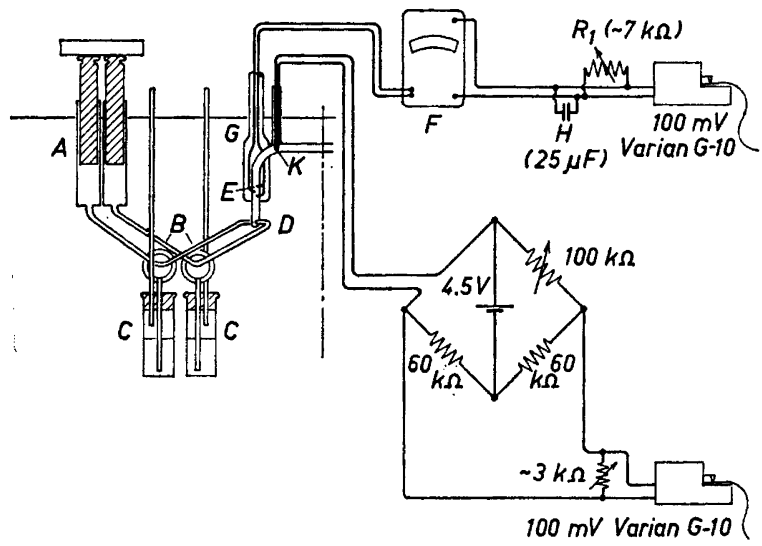

Fig. 1. Diagram of stopped-flow apparatus.

Acta Chem. Scand. 20 (1966) No. 7 
by the oscillator of the conductivity meter, F. The cables from the platinum rings are protected by an outer glass jacket $G$. The effective volume of mixing has been estimated to $0.05 \mathrm{ml}$. With the normal rate of injection, $3 \mathrm{ml} / \mathrm{sec}$, the mixing time is therefore 0.017 sec. Full advantage cannot be taken of this short time, because $0.7 \mathrm{ml}$ of mixture must be injected in order to cover the platinum rings. On this account the first $0.23 \mathrm{sec}$ after mixing cannot be investigated.

From the conductivity meter F (Radiometer type CDM 2d) a signal is taken out to a $100 \mathrm{mV}$ recorder (Varian G-10). By means of the resistance $R_{1}$, the recorder deflection may be adjusted relative to conductivity. The ripple voltage of the signal is smoothened by the condenser, $\mathrm{H}$, of $25 \mu \mathrm{F}$. The maximum paper speed is $0.6 \mathrm{~cm} / \mathrm{sec}$, the paper width is $13 \mathrm{~cm}$, the maximum pen speed when applying a fullspan step function is $18 \mathrm{~cm} / \mathrm{sec}$. Although this balancing time is too slow to permit full-scale recording of reactions having firstorder rate constants higher than $1.5 \mathrm{sec}^{-1}$, it is still possible to trace the last part of runs of reactions having rate constants up to about $4 \mathrm{sec}^{-1}$, since this corresponds to the pen response when applying a step function corresponding to 1/3 or less of the full span.

The temperature of the reacting mixture was measured with a $100 \mathrm{kohm}$ thermistor, $\mathrm{K}$, placed as close as possible to the outlet of the conductivity cell. The recording of the temperature was done automatically by means of a bridge and a Varian recorder. Changes up to $2^{\circ}$ in temperature at the outlet of the cell could be detected within 2 sec with an accuracy of $\pm 0.05^{\circ}$.

During the experiments the syringes, reservoirs, mixer and conductivity cell were immersed in a water bath thermostated to within $\pm 0.05^{\circ}$. Isothermal conditions are, however, hardly possible to achieve with fast reactions. In the present investigation the main difficulty is the heat of mixing of water and acetone. By mixing equal volumes of acetone and water the temperature will increase several centigrades, but when such $50 \mathrm{vol.} \%$ mixture again is mixed with an equal volume of acetone of the same tempera. ture, a negative heat effect is observed. There is a point where no heat is absorbed or evolved, and experiments showed that this is 61.2 vol.\% water in acetone mixed with an equal volume of acetone. Similarly, equal volumes of pure dioxan and $70.6 \mathrm{vol} . \%$ water in dioxan did not show any heat effect at mixing.

Since it was not possible to measure the temperature in the centre of the conductivity cell, and since it cannot be assumed that the temperature recorded at the outlet of the cell provides a reliable measurement for the reaction temperature when the heat of mixing becomes appreciable, most runs were made using the solvents 30.6 vol. $\%$ water in acetone and $35.3 \mathrm{vol} . \%$ water in dioxan. (Percentages are given by volume prior to mixing at $25^{\circ}$ ).

Procedure for measurements. After rinsing the apparatus with pure acetone and after excluding air bubbles, the one reservoir was filled with the solution of anhydride, and the other with the aqueous solution. The syringes were repeatedly filled from the reservoirs and discharged through the mixer before measurements were started. The concentration of the anhydride solution were usually adjusted to give an equilibrium conductivity of $350-450 \mu \mathrm{mho}$, and the recorder was calibrated to give zero deflection for zero conductivity, and $90 \%$ of full-scale for $450 \mu \mathrm{mho}$.

About 3-5 ml of reaction mixture were then discharged manually into the conductivity cell by applying a firm, sharp push on the pistons. The conductivity recorder instantaneously reacted to show a low reading showing that the liquid in the cell had been displaced by a fresh mixture of reactants. As soon as the push was released the conductivity increased due to the increasing concentration of sulphonic acid in the cell. When the reading had become constant the measurement was repeated by a new discharge from the syringes. At least 3, and usually 6-9 runs were made for a given set of parameters.

Analysis of recorded curves. From the recorded curves, see Fig. 2, 8-15 readings were taken at equidistant time intervals, an early value (less than 0.5 sec after mixing) being selected as zero time. The readings were transformed to concentrations $(C)$ by means of a calibration curve (cf. below), and the values of $\log \left(C_{\infty}-C\right) /\left(C_{\infty}-C_{0}\right)$ were plotted versus time. From the slope of the plot the pseudo first order rate constant $k$ was calculated. Average values of $k$, together with standard deviations and numbers of repeated runs, have been presented in Table 1 .

Six calibration plots, relating recorder readings to acid concentrations, were made with series of solutions of $p$-toluene sulphonic acid and $p$-bromobenzene sulphonic acid

Acta Chem. Scand. 20 (1966) No. 7 

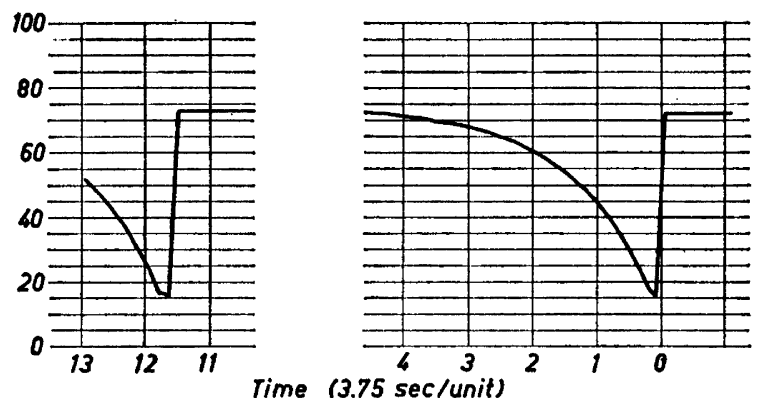

Fig. 2. Automatically recorded curves for hydrolysis of $3.00 \times 10^{-3} \mathrm{M}\left(p-\mathrm{BrC}_{6} \mathrm{H}_{4} \mathrm{SO}_{2}\right)_{2} \mathrm{O}$ in 30.6 vol. $\%$ water in acetone at $16.0^{\circ} \mathrm{C}$.

having normalities $10^{-4}-7 \times 10^{-3}$ in the solvents 30.6 vol. $\%$ water in acetone and 35.3 vol. $\%$ water in dioxan, at $15^{\circ}, 25^{\circ}$, and $35^{\circ}$. The deviations from linearity of the calibration curves were appreciable, partly due to a nonlinear recording of the conductivity signal, partly due to the fact that the conductivity is not proportional to the concentration of a strong acid in these solvents (cf. Ref. 9). The variations in rate constants found by applying different calibration plots to one and the same run was about $1 \%$ relative, which is not more than the uncertainty in the graphical determination of the rate constant.

Check of apparatus. Measurements were made on the hydrolysis of acetyl chloride (analytical grade from Merck, refluxed and distilled) in 30.6 vol. \% water in acetone at 15.3. A rate constant for the same compound, solvent composition and temperature was extrapolated from data reported by Cairns and Prausnitz. The extrapolated figure is $1.15 \pm 0.07 \mathrm{sec}^{-1}$, which is in satisfactory agreement with the result obtained in this investigation, $1.12 \pm 0.03 \mathrm{sec}^{-1}$.

\section{RESULTS AND DISCUSSION}

Pseudo first order kinetics. Typical plots are shown in Fig. 3. The linearity of the plots to at least $95 \%$ hydrolysis classifies the kinetics as first order with respect to the substrate. In a number of runs the initial concentration of the substrate was the parameter varied. From the results given in Table 2,

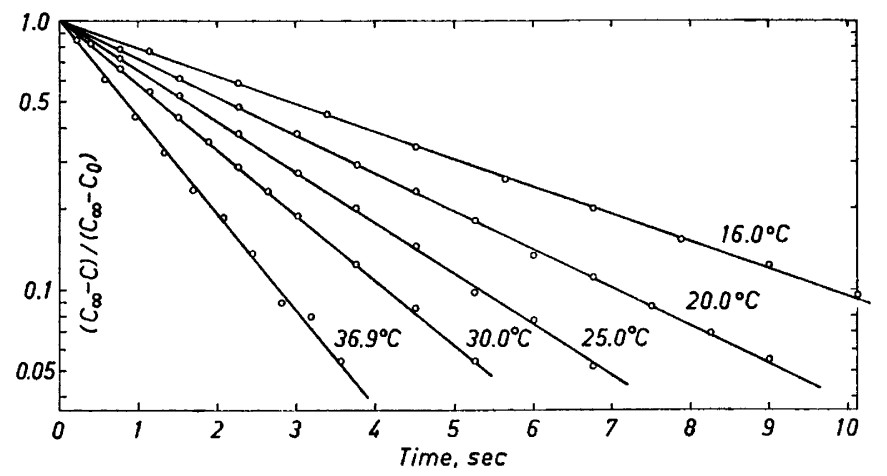

Fig. 3. First order plots for the hydrolysis of bromobenzene sulphonic anhydride in 30.6 vol. \% water in acetone at various temperatures. 
Table 1. Rate data for hydrolysis of sulphonic anhydrides in 30.6 vol.\% water in acetone (I) and in 35.3 vol.\% water in dioxan (II)

\begin{tabular}{|c|c|c|c|c|c|c|}
\hline $\begin{array}{c}\begin{array}{c}\text { Init. conc. of } \\
\text { substrate } \\
10^{3} \times \text { mole } / \text { litre }\end{array}\end{array}$ & Temp. ${ }^{\circ} \mathrm{C}$ & $\begin{array}{c}\text { Rate constan } \\
\text { sec }^{-1}\end{array}$ & & $\begin{array}{l}\text { Standard } \\
\text { deviation }\end{array}$ & $\begin{array}{c}\text { Number } \\
\text { of runs }\end{array}$ & \\
\hline $\begin{array}{c}\left(p \cdot \mathrm{CH}_{3} \mathrm{C}_{8} \mathrm{H}_{4} \mathrm{SO}_{2}\right)_{2} \mathrm{C} \\
3.06 \\
- \\
= \\
\overline{-} \\
0.31\end{array}$ & $\begin{array}{l}\text { O(I) } \\
16.0 \\
20.5 \\
25.0 \\
29.8 \\
35.0 \\
42.1\end{array}$ & $\begin{array}{l}0.0167 \\
0.0258 \\
0.0331 \\
0.051 \\
0.071 \\
0.105 \\
\end{array}$ & $\begin{array}{l} \pm \\
\pm \\
\pm \\
\pm \\
\pm \\
\pm\end{array}$ & $\begin{array}{l}0.0008 \\
0.0013 \\
0.0007 \\
0.003 \\
0.003 \\
0.008\end{array}$ & $\begin{array}{l}\mathbf{5} \\
\mathbf{5} \\
\mathbf{6} \\
\mathbf{3} \\
\mathbf{6} \\
\mathbf{4}\end{array}$ & $\begin{array}{l}\Delta H^{\neq}=12.3 \mathrm{kcal} \\
\Delta S^{\neq}=-24.2 \mathrm{e.u} .\end{array}$ \\
\hline $\begin{array}{c}\left(\mathrm{C}_{6} \mathrm{H}_{5} \mathrm{SO}_{2}\right)_{2} \mathrm{O}(\mathrm{I}) \\
3.02 \\
- \\
= \\
= \\
\end{array}$ & $\begin{array}{l}15.0 \\
20.0 \\
25.0 \\
29.9 \\
34.8\end{array}$ & $\begin{array}{l}0.0388 \\
0.0547 \\
0.0763 \\
0.1062 \\
0.139 \\
\end{array}$ & $\begin{array}{l} \pm \\
\pm \\
\pm \\
\pm \\
\pm\end{array}$ & $\begin{array}{l}0.0013 \\
0.0011 \\
0.0012 \\
0.0023 \\
0.006 \\
\end{array}$ & $\begin{array}{l}6 \\
\mathbf{9} \\
\mathbf{6} \\
\mathbf{5} \\
\mathbf{6} \\
\end{array}$ & $\begin{array}{l}\Delta H^{\neq}=11.0 \mathrm{kcal} \\
\Delta S^{\ddagger}=-26.7 \mathrm{e.u} .\end{array}$ \\
\hline $\begin{array}{c}\left(p-\mathrm{ClC}_{6} \mathrm{H}_{4} \mathrm{SO}_{2}\right)_{2} \mathrm{O}( \\
\mathbf{3 . 2 5} \\
- \\
- \\
- \\
\end{array}$ & I) $\begin{array}{l}15.0 \\
20.0 \\
25.0 \\
30.1 \\
34.8 \\
\end{array}$ & $\begin{array}{l}0.200 \\
0.282 \\
0.395 \\
0.503 \\
0.677 \\
\end{array}$ & $\begin{array}{l} \pm \\
\pm \\
\pm \\
\pm \\
\pm\end{array}$ & $\begin{array}{l}0.007 \\
0.004 \\
0.006 \\
0.013 \\
0.026 \\
\end{array}$ & $\begin{array}{l}7 \\
7 \\
7 \\
5 \\
6 \\
\end{array}$ & $\begin{array}{l}\Delta H^{\neq}=10.4 \mathrm{kcal} \\
\Delta S^{\neq}=-25.7 \mathrm{e.u} .\end{array}$ \\
\hline $\begin{array}{c}\left(p-\mathrm{BrC}_{6} \mathrm{H}_{4} \mathrm{SO}_{2}\right)_{2} \mathrm{O}( \\
\mathbf{3 . 0 0} \\
- \\
- \\
- \\
\end{array}$ & (I) $\begin{array}{l} \\
16.0 \\
20.5 \\
25.0 \\
30.0 \\
36.8 \\
\end{array}$ & $\begin{array}{l}0.239 \\
0.326 \\
0.429 \\
0.579 \\
0.88 \\
\end{array}$ & $\begin{array}{l} \pm \\
\pm \\
\pm \\
\pm \\
\pm\end{array}$ & $\begin{array}{l}0.005 \\
0.007 \\
0.005 \\
0.017 \\
0.03 \\
\end{array}$ & $\begin{array}{l}6 \\
6 \\
\mathbf{3} \\
\mathbf{5} \\
\mathbf{6} \\
\end{array}$ & $\begin{array}{l}\Delta H^{\neq}=10.5 \mathrm{kcal} \\
\Delta S^{\neq}=-24.9 \mathrm{e.u} .\end{array}$ \\
\hline $\begin{array}{c}\left(p-\mathrm{IC}_{6} \mathrm{H}_{4} \mathrm{SO}_{2}\right)_{2} \mathrm{O}(\mathrm{I}) \\
3.00 \\
- \\
- \\
- \\
\end{array}$ & $\begin{array}{l}15.0 \\
20.0 \\
25.0 \\
30.0 \\
35.0\end{array}$ & $\begin{array}{l}0.212 \\
0.282 \\
0.373 \\
0.528 \\
0.706 \\
\end{array}$ & $\begin{array}{l} \pm \\
\pm \\
\pm \\
\pm \\
\pm\end{array}$ & $\begin{array}{l}0.006 \\
0.009 \\
0.024 \\
0.015 \\
0.023 \\
\end{array}$ & $\begin{array}{l}6 \\
6 \\
6 \\
6 \\
6 \\
6 \\
\end{array}$ & $\begin{array}{l}\Delta H^{\neq}=10.3 \mathrm{kcal} \\
\Delta S^{\neq}=-25.8 \text { e.u. }\end{array}$ \\
\hline $\begin{array}{c}\left(m-\mathrm{NO}_{2} \mathrm{C}_{6} \mathrm{H}_{4} \mathrm{SO}_{2}\right) \\
10.0 \\
\end{array}$ & $\mathrm{O}(\mathrm{I})$ & 2.56 & \pm & 0.13 & 3 & \\
\hline $\begin{array}{c}\mathrm{CH}_{3} \mathrm{COCl}(\mathrm{I}) \\
7.0 \\
\end{array}$ & 15.3 & 1.12 & \pm & 0.03 & 7 & \\
\hline $\begin{array}{c}\left(p-\mathrm{CH}_{3} \mathrm{C}_{6} \mathrm{H}_{4} \mathrm{SO}_{2}\right)_{2} \mathrm{C}_{3.07} \\
- \\
-\end{array}$ & $\begin{array}{r}\text { O(II) } \\
16.0 \\
25.0 \\
33.8 \\
\end{array}$ & $\begin{array}{l}0.0229 \\
0.0455 \\
0.0921\end{array}$ & $\begin{array}{l} \pm \\
\pm \\
\pm\end{array}$ & $\begin{array}{l}0.0014 \\
0.0026 \\
0.0013\end{array}$ & $\begin{array}{l}3 \\
4 \\
4 \\
\end{array}$ & $\begin{array}{l}\Delta H^{\neq}=13.2 \mathrm{kcal} \\
\Delta S^{\neq}=-20.4 \text { e.u. }\end{array}$ \\
\hline $\begin{array}{c}\left(p-\mathrm{BrC}_{6} \mathrm{H}_{4} \mathrm{SO}_{2}\right)_{2} \mathrm{O}( \\
\mathbf{3 . 0 0} \\
= \\
= \\
= \\
=\end{array}$ & $\begin{aligned} & \text { (II) } \\
& 16.0 \\
& 20.5 \\
& 25.0 \\
& 29.9 \\
& 34.8 \\
& 39.8\end{aligned}$ & $\begin{array}{l}0.232 \\
0.331 \\
0.442 \\
0.627 \\
0.844 \\
1.097\end{array}$ & $\begin{array}{l} \pm \\
\pm \\
\pm \\
\pm \\
\pm \\
\pm\end{array}$ & $\begin{array}{l}0.005 \\
0.007 \\
0.013 \\
0.017 \\
0.021 \\
0.04\end{array}$ & $\begin{array}{l}3 \\
7 \\
\mathbf{6} \\
7 \\
7 \\
\mathbf{7} \\
6\end{array}$ & $\begin{array}{l}\Delta H^{\neq}=11.3 \mathrm{kcal} \\
\Delta S^{\neq}=-22.0 \mathrm{e.u} .\end{array}$ \\
\hline
\end{tabular}

Acta Chem. Scand. 20 (1966) No. 7 
Table 2. Rate data for hydrolysis of $p$-bromobenzenesulphonic anhydride in 30.6 vol.\% water in acetone at $25.0^{\circ}$.

\begin{tabular}{cclr}
\hline & Init.conc. & \\
No. & $10^{3} \mathrm{M}$ & Added electrolyte & Rate constant $\sec ^{-1}$ \\
\hline & & & \\
1 & 3.01 & 0 & $0.432 \pm 0.015(7)$ \\
2 & 1.50 & 0 & $0.426 \pm 0.005(8)$ \\
3 & 0.66 & 0 & $0.438 \pm 0.027(9)$ \\
4 & 0.66 & $0.010 \mathrm{M} \mathrm{NaCl}$ & $0.449 \pm 0.030(7)$ \\
5 & 0.66 & $0.010 \mathrm{M} \mathrm{LiCl}$ & $0.457 \pm 0.015(8)$ \\
6 & 0.89 & $0.010 \mathrm{M} \mathrm{Na-bromobenzenesulphonate}$ & $0.450 \pm 0.040(7)$ \\
7 & 0.66 & $0.005 \mathrm{M}$ bromobenzenesulphonic acid & $0.445 \pm 0.017(10)$ \\
8 & 0.89 & $0.010 \mathrm{M} \mathrm{NaOH}$ & $\geq 1.40$
\end{tabular}

experiments Nos. 1-3, it will be seen that no significant change in the rate constant is observed. This corroborates the first order kinetics.

Effect of added electrolytes. In a number of runs the effect of adding electrolytes to the reaction mixture was studied, $c f$. Table 2 . The absence of acid catalysis shows that the hydrolysis in acid and neutral solutions is produced by neutral water molecules. The concentration of water in the solvent investigated is 17 mole per liter. By expressing the second order hydrolysis constant as $k_{2}=k_{1} /\left[\mathrm{H}_{2} \mathrm{O}\right], k_{2}$ for hydrolysis by water molecules is calculated to be $2.5 \times 10^{-2} \mathrm{l} \cdot \mathrm{sec}^{-1} \mathrm{~mole}^{-1}$. The corresponding value for hydrolysis produced by hydroxyl ions is $\geq(1.4-0.4) / 0.01=10^{2} l \cdot \mathrm{sec}^{-1} \cdot \mathrm{mole}^{-1}$. This marked increase in rate of hydrolysis caused by hydroxyl ions is in accordance with an $\mathrm{S}_{\mathrm{N}} 2$ substitution but does not correspond to an $\mathrm{S}_{\mathrm{N}} 1$ ionization. The small, barely significant increase in rate caused by the addition of a common-ion salt as well as of a non-common-ion salt also points towards an $\mathrm{S}_{\mathrm{N}} 2$ mechanism, cf. Ref. 10, p. 362. This $\mathrm{S}_{\mathrm{N}} 2$ mechanism is in perfect agreement with previous results from studies on the hydrolysis of sulphonyl chlorides in similar mixed solvents. ${ }^{1}$

Influence of solvent composition. The results showing the influence of varying the water concentration on the hydrolysis rate of p-bromobenzene sulphonic anhydride at $25^{\circ}$ can be presented in a diagram with log $k$ as ordinate and $\log$ molar water concentration as abscissa. The plot (not shown) is fairly linear with a slope of 1.75. Since the water constitutes a high proportion of the solvent, this result cannot be rationalised simply in terms of molecularity of the reacting water. It is, however, of interest that slopes of 1-2 usually signify $\mathrm{S}_{\mathrm{N}} 2$ reactions, whereas $\mathrm{S}_{\mathrm{N}} 1$ reactions normally show slopes of 5-7.1 An alternative way of representing these data have been shown in Fig. 4. In this diagram the $\log k$ values have been plotted versus the ionising power of the medium, Y, as defined by Grunwald and Winstein; cf. Ref. 11, p. 297. The plot shows a good linear correlation with a slope $m=0.42$. The fact that the $m$ value does not increase when increasing the water content suggests that the $\mathrm{S}_{\mathrm{N}} 2$ mechanism operates over the whole range from 10 to $50 \mathrm{vol} . \%$ water in acetone. It is of interest to note that the $m$ value to be derived from the data of Vizgert for the $\mathrm{S}_{\mathrm{N}} 2$ hydrolysis of sulphonyl chlorides in dioxanwater mixtures at least up to $40 \%$ water also is 0.42 (cf. Ref. 1, Fig. 5). 


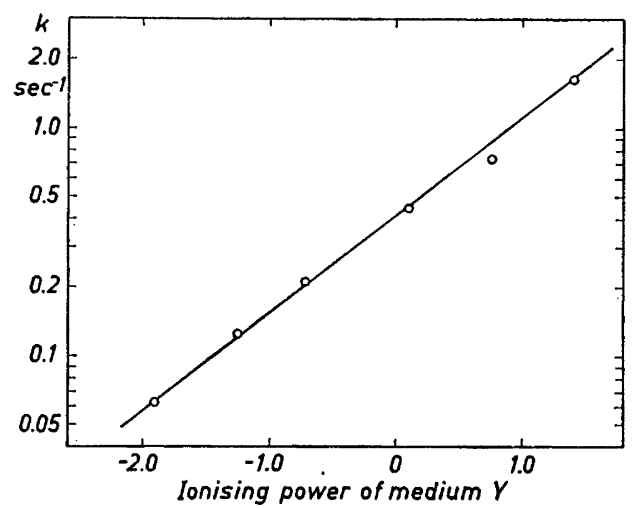

Fig. 4. Rate data for the hydrolysis of bromobenzene sulphonic anhydride at $25.0^{\circ}$ in dependence of the solvating power of the medium as defined by GrunwaldWinstein ${ }^{11}$ for various mixtures of water and acetone.

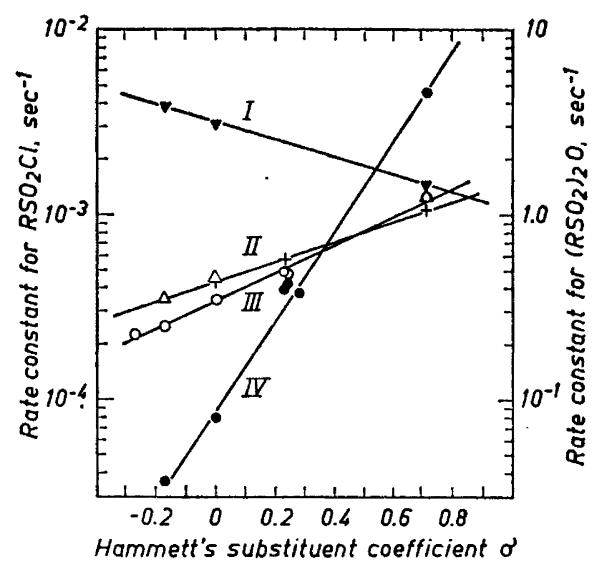

Fig. 5. Plots of $\log k$ against Hammett's substituent coefficients $\sigma,^{12}$ for the hydrolysis of sulphonyl chlorides and sulphonic anhydrides. I: $\mathrm{RSO}_{2} \mathrm{Cl}$ in pure water at $25^{\circ}$ (Hedlund ${ }^{13}$ ). II: $\mathrm{RSO}_{2} \mathrm{Cl}$ in $50 \%$ water in acetone at $30^{\circ}$ (Linetskaya ${ }^{14}+$ and Hedlund ${ }^{13} \triangle$ ). III: $\mathrm{RSO}_{2} \mathrm{Cl}$ in $30 \%$ water in dioxan at $50^{\circ}$ (Vizgert $\left.{ }^{1}\right)$. IV: $\left(\mathrm{RSO}_{2}\right)_{2} \mathrm{O}$ in 30.6 vol. \% water in acetone at $25^{\circ}$ (this work). The value for $\left(m-\mathrm{NO}_{2} \mathrm{C}_{6} \mathrm{H}_{4} \mathrm{SO}_{2}\right)_{2} \mathrm{O}$ has been extrapolated from the rate at $15^{\circ}$ assuming $\Delta H^{\neq}=10 \mathrm{kcal}$.

Influence of ring substituent. According to Hammett ${ }^{12}$ the rate constant $k$ for a reaction involving a substituted compound may often be related to the rate constant $k_{0}$ for the same reaction of the corresponding unsubstituted compound by| the equation: $\log k-\log k_{0}=\varrho \times \sigma$. Here, $\varrho$ is a reaction constant independent of the nature of the substituent but characteristic of the type of reaction, while $\sigma$ is a substituent constant independent of reaction type. The latter constant is defined as the logarithm of the ratio of the ionization constant of the similarly substituted benzoic acid to the ionization constant of unsubstituted benzoic acid.

In Fig. 5 the logarithm of rate constants for the hydrolysis of sulphonyl chlorides and sulphonic anhydrides have been plotted against Hammett's substituent coefficients, $\sigma$. Each of the four series shows a linear relationship with different slopes, corresponding to different $\varrho$-values.

For the hydrolysis of sulphonyl chlorides in pure water an $\mathrm{S}_{\mathrm{N}} 1$ mechanism has been inferred: 1

$$
\begin{aligned}
& \mathrm{RC}_{6} \mathrm{H}_{4} \mathrm{SO}_{2} \mathrm{Cl} \rightleftharpoons \mathrm{RC}_{6} \mathrm{H}_{4} \mathrm{SO}_{2}{ }^{+}+\mathrm{Cl}^{-} \quad \text { (rate determining) } \\
& \mathrm{RC}_{6} \mathrm{H}_{4} \mathrm{SO}_{2}++\mathrm{H}_{2} \mathrm{O} \longrightarrow \mathrm{RC}_{6} \mathrm{H}_{4} \mathrm{SO}_{3} \mathrm{H}+\mathrm{H}^{+} \text {(fast) }
\end{aligned}
$$




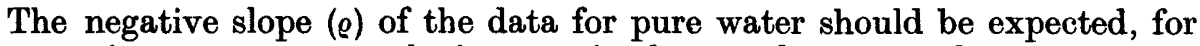
the quantity $-\sigma$ measures the increase in electron density at the reaction site produced by the substituent $R$, and the rate determining ionization according to the above equation must be favoured with increasing electron density at the sulphur atom.

When the hydrolysis of the sulphonyl chlorides proceeds by an $\mathrm{S}_{\mathrm{N}} 2$ substitution, as is inferred ${ }^{\mathbf{1}}$ for the mixtures of water and acetone or dioxan:

$$
\mathrm{RC}_{6} \mathrm{H}_{4} \mathrm{SO}_{2} \mathrm{Cl}+\mathrm{H}_{2} \mathrm{O} \rightleftharpoons \mathrm{RC}_{6} \mathrm{H}_{4}-\underset{\substack{\uparrow \\ \stackrel{\uparrow}{\mathrm{S}} \mathrm{O}^{\prime} \mathrm{OH}_{2}}}{\mathrm{O} \mathrm{Cl}} \longrightarrow \mathrm{RC}_{6} \mathrm{H}_{4} \mathrm{SO}_{3} \mathrm{H}+\mathrm{H}^{+}+\mathrm{Cl}^{-}
$$

(transition state)

the effect of decreasing $\sigma$ will still be to ease rupture of the $\mathrm{S}-\mathrm{Cl}$ bond, but another effect will tend to balance the former, namely the increasing resistance against nucleophilic attack from the water molecule. It follows therefore that the $\varrho$ value for such hydrolysis should become less negative or even positive, and the data presented in Fig. 5 confirm this conclusion.

Turning now to the hydrolysis of sulphonic anhydrides, and assuming an $\mathrm{S}_{\mathrm{N}} 2$ mechanism for this process

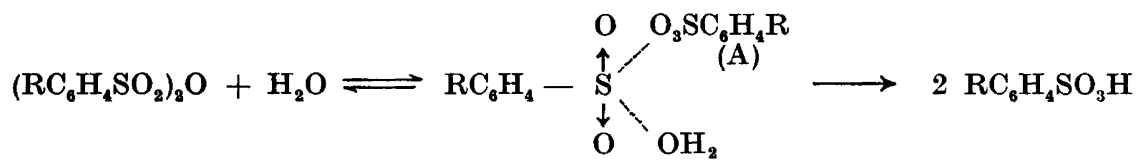

(transition state)

it may be noticed when comparing (4) with (3) that there are now two additional effects from the substituent in the leaving anion (A) to be taken into account. Firstly, decreasing $\sigma$-values will give an extra contribution to the electron density at the reaction site to repel water attack. Secondly, increasing $\sigma$ values will favour the formation of the anion A. Both effects should raise the $\varrho$-value, in accordance with the experimental data.

Absolute values of rate constants. From the data relating to mixed solvents in Fig. 5 it will appear that the rate of hydrolysis is 100-4000 times faster for the anhydrides than for the chlorides. Although the media used for the investigations are not strictly identical it may safely be concluded that such large differences must be ascribed to the different substrates. The qualitative experience concerning the higher reactivity of the sulphonic anhydrides compared to the sulphonyl chlorides ${ }^{2}$ has therefore been confirmed.

It is of interest to know whether this difference is enthalpy or entropy controlled. For each set of runs Arrhenius plots were made, some of which are shown in Fig. 6. From the slope of these plots the energies of activation $E$ cal were calculated, and from $E$ and the rate constant at $25^{\circ}$ the value of $\log A$ of the Arrhenius equation was obtained $(\log A=\log k+E / T \times 4.575)$. Finally $\Delta H^{\ddagger}$, the enthalpy of activation, and $\Delta S^{\ddagger}$, the entropy of activation, 


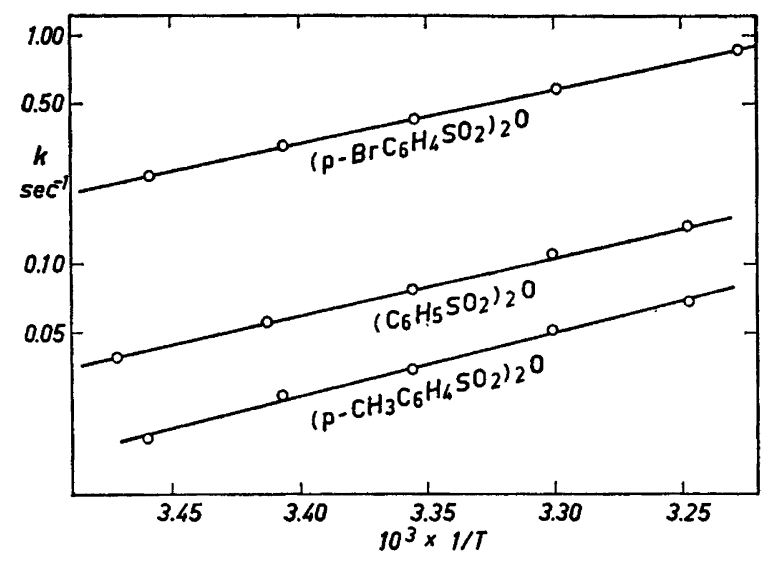

Fig. 6. Arrhenius plots for the hydrolysis of various sulphonic anhydrides in 30.6 vol.\% water in acetone.

were calculated for each component, $\Delta H^{\neq}$(cal) $=E-600$ and $\Delta S^{\neq}$(e.u.) $=$ $4.575 \times \log A-60.53$, cf. Ref. 11, p. 71. Both activation parameters are included in Table 1.

In Table 3 some values of $\Delta H^{\neq}$(in kcal) and $\Delta S^{\neq}$(in e.u.) have been compiled. Unfortunately none of the available data for the two types of compounds relates to identical solvent composition. Under this circumstance it appears that the best comparison possible should be between the data in column III and in column IV. It may be argued that the difference in $\Delta G^{\neq}$ caused by the difference between $30 \%$ water in dioxan and $30 \%$ water in acetone is small. Thus the solvolysis rate constant at $25^{\circ}$ for t-butyl chloride is 1.31 times greater in the latter than in the former solvent, ${ }^{11}$ corresponding

Table 3. Activation parameters for hydrolysis of sulphonyl chlorides and sulphonic anhydrides.

I: $\mathrm{RSO}_{2} \mathrm{Cl}$ in pure water (Hedlund ${ }^{13}$ )

II: $\mathrm{RSO}_{2} \mathrm{Cl}$ in $50 \%$ water in acetone (Linetskaya ${ }^{14}$ and Hedlund ${ }^{13}$ )

III: $\mathrm{RSO}_{2} \mathrm{Cl}$ in $30 \%$ water in dioxan (Vizgert ${ }^{1}$ )

IV: $\left(\mathrm{RSO}_{2}\right)_{2} \mathrm{O}$ in 30.6 vol. \% water in acetone (this work)

$\mathrm{V}$ : $\left(\mathrm{RSO}_{2}\right)_{2} \mathrm{O}$ in 35.3 vol. \% water in dioxan (this work).

\begin{tabular}{|c|c|c|c|c|c|c|c|c|c|c|}
\hline \multicolumn{1}{|c|}{$\mathbf{R}$} & \multicolumn{5}{|c|}{$\Delta H^{\neq} \mathrm{kcal}$} & \multicolumn{5}{|c|}{$\Delta S \neq$ e.u. } \\
\hline & I & II & III & IV & V & I & II & III & IV & V \\
\hline$p-\mathrm{CH}_{3} \mathrm{C}_{6} \mathrm{H}_{4}$ & 17.4 & 13.7 & 13.2 & 12.2 & 13.2 & -11.3 & -29.2 & -34.3 & -24.2 & -20.4 \\
$\mathrm{C}_{6} \mathrm{H}_{5}$ & 16.8 & 13.8 & 12.8 & 11.0 & - & -13.5 & -28.5 & -36.3 & -26.7 & - \\
$p-\mathrm{ClC}_{6} \mathrm{H}_{4}$ & - & 13.3 & 11.7 & 10.4 & - & - & -29.5 & -37.6 & -25.7 & - \\
$p-\mathrm{BrC}_{8} \mathrm{H}_{4}$ & - & - & 11.7 & 10.5 & 11.3 & - & - & -37.4 & -24.9 & -22.0 \\
\hline
\end{tabular}

Acta Chem. Scand. 20 (1966) No. 7 
to a difference in $\Delta G^{\neq}$of $0.16 \mathrm{kcal}$. Furthermore, the rate constant for the hydrolysis of $p$-toluenesulphonyl chloride at $30^{\circ}$ is only 1.15 times greater in $50 \%$ water in acetone than in $50 \%$ water in dioxan (calculation based on data reported by Hedlund ${ }^{13}$ and Vizgert ${ }^{1}$ ). In spite of these examples, it is not certain that differences in $\Delta S^{\neq}$and $\Delta H^{\neq}$will be small. Therefore some runs were made with anhydrides in 35.3 vol. \% water in dioxan (it was impossible to avoid a heat effect when using $30 \mathrm{vol} . \%$ water in dioxan). The results are shown in columns $\mathrm{V}$ in the table, and it will appear that they do not deviate greatly from the results in columns IV. A direct comparison between columns III and columns IV is therefore permissible. It will be seen that the greater rate in the anhydride hydrolysis is mainly caused by a higher $\Delta S^{\neq}$, the difference being of the order of $10 \mathrm{e.u}$. This difference is due most probably to differences in the change of structure of the solvent shell during the transformation of the less polar reactants to the more polar transition states. The solvation entropy of the benzenesulphonate ion has not been measured, but it may be indicative that the partial molal entropies for the aqueous hydrogensulphate ion, $\mathrm{HSO}_{4}^{-}$, and for the aqueous hydrogensulphite ion, $\mathrm{HSO}_{3}{ }^{-}$, are 32.6 and 30.6 e.u., respectively. ${ }^{15}$ The corresponding value for the chloride ion is only $13.5 \mathrm{e}$.u; thus it appears that the difference in reaction rates can be rationalised in terms of solvation effects of the transition states.

The somewhat different values for the chloride data in pure water, col. I, bear out the different mechanism operating in this solvent. It is not unlikely that a shift in mechanism also will be observed in the anhydride hydrolysis, when the water content is increased above 50 vol. \%.

\section{REFERENCES}

1. Vizgert, R. V. Usp. Khim. 32 (1963) 3.

2. Field, L. J. Am. Chem. Soc. 74 (1952) 394.

3. Bojesen, E. and Degn, H. Acta Endocrinol. 37 (1961) 541.

4. Thuneberg, L. Intern. J. Appl. Radiation Isotopes 16 (1965) 413.

5. Gilbert, E. E. and Veldhius, B. Ind. Eng. Chem. 47 (1955) 2300.

6. Christensen, N. H. Acta Chem. Scand. 18 (1964) 954.

7. Christensen, N. H. Acta Chem. Scand. 15 (1961) 1507.

8. Lukashevich, V. O. Dokl. Akad. Nauk SSSR 114 (1957) 1025.

9. Cairns, E. J. and Prausnitz, J. M. J. Chem. Phys. 32 (1960) 169.

10. Ingold, C. K. Structure and Mechanism in Organic Chemistry, Cornell University Press, New York 1953.

11. Leffler, J. E. and Grunwald, E. Rates and Equilibria of Organic Reactions, Wiley, New York and London 1963.

12. Hammett, L. P. Physical Organic Chemistry, McGraw, New York and London 1940, Chapter 7.

13. Hedlund, I. Arkiv Kemi, Mineral. Geol. 14 A (1940) No. 6.

14. Linetskaya, Z. G. and Sapozhnikova, I. V. Dokl. Akad. Nauk SSSR 86 (1952) 763.

15. Latimer, W, M., Pitzer, K. S. and Smith, W. V. J. Am. Chem. Soc. 60 (1938) 1829.

Received March 21, 1966. 